\title{
Sex estimation using subpubic angle from reconstructed three-dimensional computed tomography pelvic model in a contemporary Malaysian population
}

\author{
Siti Hanum Mohd $\mathrm{Ali}^{1,2}$, Normaliza Omar ${ }^{1,2}$, Mohamed Swarhib Shafie ${ }^{1}$, Nik Azuan Nik Ismail ${ }^{3}$, \\ Helmi Hadi ${ }^{4}$, Faridah Mohd Nor ${ }^{1}$ \\ ${ }^{1}$ Forensic Unit, Department of Pathology, Universiti Kebangsaan Malaysia Medical Centre, Kuala Lumpur, ${ }^{2}$ Department of Basic Medical Science I, Faculty \\ of Medicine and Health Sciences, Universiti Sains Islam Malaysia, Kuala Lumpur, ${ }^{3}$ Radiology Department, Universiti Kebangsaan Malaysia Medical Centre, \\ Kuala Lumpur, ${ }^{4}$ School of Health Sciences, Universiti Sains Malaysia, Kubang Kerian, Malaysia
}

\begin{abstract}
Research in forensic anthropology is recent in Malaysia due to limited access to documented skeletal collections. However, advanced imaging techniques provide virtual bone samples for use in morphometric studies to establish populationspecific standards by virtual anthropology. This study examined sexual dimorphism in the subpubic angle using a threedimensional computed tomography model of the pelvis, in a contemporary Malaysian population. The sample comprised multidetector computed tomography (MDCT) scans of 50 male and 50 female adults. Segmentation of the MDCT scans was performed using 3D Slicer, and four landmarks were acquired using Stratovan Checkpoint for the subpubic angle measurement. The technical error of measurement (TEM), relative TEM, and coefficient of reliability (R) exhibited high reliability in measurements. Results showed that the subpubic angle in males was $68.6^{\circ} \pm 7.6^{\circ}$ and in females $87.4^{\circ} \pm 6.5^{\circ}$. The subpubic angle in females was significantly larger than in males $(P<0.001)$. Inverse correlation was found between the subpubic angle and age, in both males $(r=-0.449, P<0.01)$ and females $(r=-0.385, P<0.01)$. The overall accuracy of sex estimation using the subpubic angle was $94 \%(P<0.001)$. The subpubic angle, with a demarcating point of $78.6^{\circ}$, showed a sensitivity and specificity of $94 \%$ in the classification of female individuals. In conclusion, sex estimation using the subpu bic angle is highly accurate, with a high degree of expected sensitivity and specificity in the Malaysian population.
\end{abstract}

Key words: Subpubic angle, Pelvis, Morphometric, Anthropology, Sexual dimorphism

Received June 17, 2019; Revised September 2, 2019; Accepted September 25, 2019

Corresponding author:

Faridah Mohd Nor (iD)

Forensic Unit, Department of Pathology, Universiti Kebangsaan Malaysia Medical Centre, Jalan Yaacob Latiff, Bandar Tun Razak, 5600o, Kuala Lumpur, Malaysia

Tel: +6o-03-91455369, Fax: +6o-03-91711673, E-mail: mnfaridah@gmail. com

\section{Introduction}

Most research in forensic anthropology focuses on finding new methods or refining the current ones. In Malaysia, we have been using the established standards, which were developed from sample populations other than ours [1-3]. However, it is well-known that skeletal characteristics differed among various populations [2, 4-9]. The different levels of sexual dimorphism across different populations have been attributed to geography, climate, genetics, ancestry, secular

\section{Copyright ( 2020 . Anatomy \& Cell Biology}

This is an Open Access article distributed under the terms of the Creative Commons Attribution Non-Commercial License (http://creativecommons.org/licenses/by-nc/4.0/) which permits unrestricted non-commercial use, distribution, and reproduction in any medium, provided the original work is properly cited. 
change, nutrition, lifestyle activities, and labors [10-16]. Climatic adaptation explains the different body size and proportions, where populations living at high latitude have larger bodies and relatively shorter limbs than those living at low latitude $[11,12]$, while populations living at low latitude were found to have a narrower body (bi-iliac) breadth [13, 16, 17]. Neutral evolutionary processes like genetic drift may also explain the pelvic shape variations in both sexes among different populations [16]. Socioeconomic improvements, science and medicine advancement and higher standards of living in certain populations, may contribute to the secular change in the pelvic traits [15]. These variations in sexual dimorphism in different populations warrant the development of population-specific standards $[14,18]$. Accordingly, researchers are actively developing their population standards to ensure accurate and reliable biological profile estimation in forensic cases, for satisfactory legal submission $[2,4,8,19]$.

Current efforts into forensic anthropological research in Malaysia are to develop standards based on the contemporary population [19-26]. Nonetheless, collections of bones in Malaysia are limited. Advances in imaging technology have seen the emergence of virtual anthropology and virtopsy [2729] in the field of forensic science and anthropology. Virtual anthropology has opened an avenue for research using virtual bone samples of living contemporary Malaysians in the form of multidetector computed tomography (MDCT) data from radiological investigations. Three-dimensional computed tomography (3DCT) models are convenient to work with and are readily available for studies [28]. Research using 3DCT models of bones require minimal preparation of samples, are non-invasive and cost-effective, and does not require large storage facilities [28]. Results of previous research had shown that there were no significant differences between real bones or 3DCT models $[29,30]$.

The subpubic angle is one of the most sexually dimorphic parts of the pelvis [31]. Previous authors have reported subpubic angle for various populations, either as subpubic angle alone or within a study that includes different pelvic parameters $[4,5,8,30,32-39]$. As research into forensic anthropology is quite recent in Malaysia, we have yet to record the subpu-

Table 1. Distribution of samples by sex and age groups

\begin{tabular}{|c|c|c|c|c|c|c|c|c|}
\hline \multirow{2}{*}{ Sex } & \multicolumn{6}{|c|}{ Age group (yr) } & \multirow{2}{*}{ Total } & \multirow{2}{*}{$\begin{array}{c}\text { Mean } \\
\text { age } \pm S D(y r)\end{array}$} \\
\hline & $20-29$ & $30-39$ & $40-49$ & $50-59$ & $60-69$ & $70-79$ & & \\
\hline Male & 8 & 10 & 12 & 4 & 8 & 8 & 50 & $47.7 \pm 17.2$ \\
\hline Female & 6 & 11 & 9 & 8 & 12 & 4 & 50 & $48.4 \pm 15.4$ \\
\hline
\end{tabular}

bic angle for this population. This study is a part of ongoing forensic anthropology research in Malaysia to establish its population-specific standards. To the best of our knowledge, this is the first data of the subpubic angle for the Malaysians. Therefore, the present study aims to quantify the subpubic angle in Malaysians, determine the demarcating point to discriminate between male and female, and analyze the accuracy of sex estimation using the subpubic angle.

\section{Materials and Methods}

\section{Materials}

The present study comprised abdominopelvic MDCT scans of 100 individuals who presented for a radiological investigation at the Radiology Department of Universiti Kebangsaan Malaysia Medical Centre (UKMMC) from 2012 to 2017. The computed tomography (CT) scans were anonymized with the patient registration number, and the sex and age data were documented. Malaysia is a multi-ethnic country. The population of Malaysia is made up of $69 \%$ Malay, 23\% Chinese, 7\% Indian, and 1\% others. The study population represented the three main ethnic groups in $\mathrm{Ma}-$ laysia, which comprised 50 males (age range, 20-78 years; mean age, $47.7 \pm 17.2$ years) and 50 females (age range, 20-79 years; mean age, $48.4 \pm 15.4$ years) (Table 1, Fig. 1). MDCT scans with abnormalities (e.g., fractures, scoliosis, hip prostheses) were excluded from the study. The ethics approval was granted by the Research and Ethics Committee of Universiti Kebangsaan Malaysia.

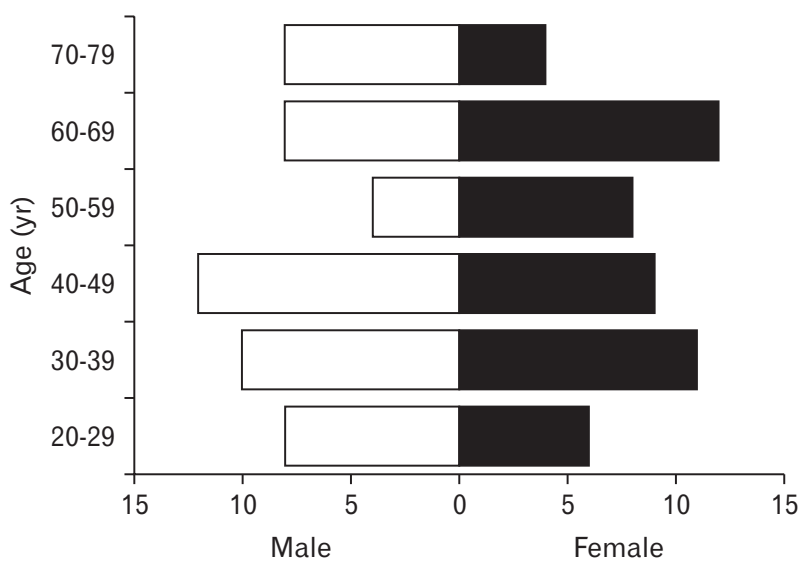

Fig. 1. Age distribution of the study sample in male and female. Age is normally distributed in the male and female groups (Shapiro-Wilk test). 


\section{Methods}

\section{Multidetector computed tomography scans segmentation}

Abdominopelvic CT imaging of the individuals was performed using MDCT on a Siemens SOMATOM Sensation 64 scanner (Siemens Medical Solutions, Forchheim, Germany) with $0.5-\mathrm{mm}$ slice thickness and auto-programmed for reconstruction at $1.0 \mathrm{~mm}$ for better spatial resolution. The CT scans were acquired from the Radiology Department UKMMC as Digital Imaging and Communications in Medicine (DICOM). The DICOM files were imported into 3D Slicer [40] for segmentation to produce 3DCT models of the pelvis. The 3D Slicer is a free, open-source software application for medical image computing that works similar to a radiology workstation. It provides visualization, segmentation, and other image processing functions. Different modules in the 3D Slicer were utilized to segment the region of interest, and to remove the unwanted parts from the CT models (i.e., femoral heads, lumbar vertebrae, soft tissues). The final 3DCT models of the pelvis were saved as polygon files (PLY) for analysis.

\section{Landmarks application and subpubic angle measurement}

Application of landmarks on the 3DCT model of the pelvis was performed using Stratovan Checkpoint (version 2018.09.07.0325). The Checkpoint can measure an angle between three or four landmarks. Due to different Hounsfield density between cartilage and bone, the pelvic cartilage was rendered absent from the 3DCT pelvic model after segmentation. Thus, four anatomical landmarks were used in the present study to accommodate for the post-segmentation gap between the right and left symphyses pubis. Landmarks were defined and illustrated (Fig. 2) [8]. Following landmarks application, a built-in, angle-measuring tool in the Checkpoint software was used to measure the subpubic angle between these four landmarks automatically. Reliability of a landmarkbased measurement depended on the repeatability of landmark identification by the observers according to the study protocol [41]. This reliability was evaluated in the technical error of measurement (TEM) study [42, 43]. Information on sex and age was withheld from the observers during the study. Measurements of the subpubic angle were performed twice by the main observer (first observer), and the average subpubic angle measurements were taken for statistical analyses [44, 45].

\section{Technical error of measurement}

A total of 20 3DCT models of the pelvis were randomly selected for assessment of measurement reliability using TEM, relative TEM (rTEM), and coefficient of reliability (R). TEM is the standard deviation between repeated measures, which is an accuracy index calculated to evaluate intra- and interobserver reliability in the measurements [42]. In the present study, the TEM for both intra- and inter-observer were calculated according to the methods described by Ulijaszek and Kerr (1999) [42] and Perini et al. (2005) [43]. For the intraobserver TEM, the main observer (first observer) measured the 20 samples twice (first and second measurements), and for the inter-observer TEM, another observer (second observer) measured the 20 samples once. TEM was calculated using Eq. (1),

$$
\mathrm{TEM}=\sqrt{\frac{\sum \mathrm{D}^{2}}{2 \mathrm{~N}}}
$$

, where $\mathrm{D}$ is the difference between the first and second measurements by the first observer (intra-observer) or the difference between measurements by the first and second observer (inter-observer), and $\mathrm{N}$ is the sample size.

Estimation of error magnitude relative to the size of mea-

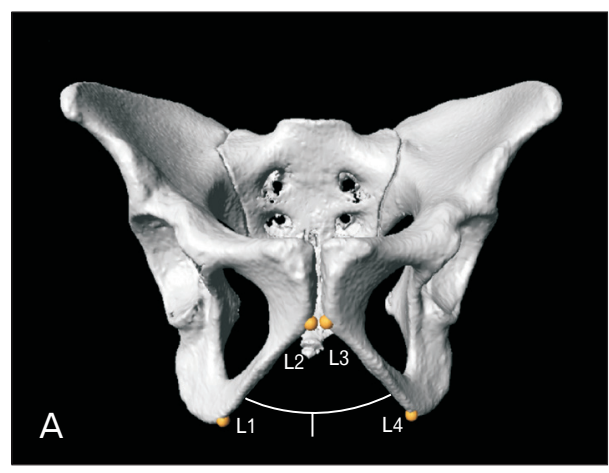

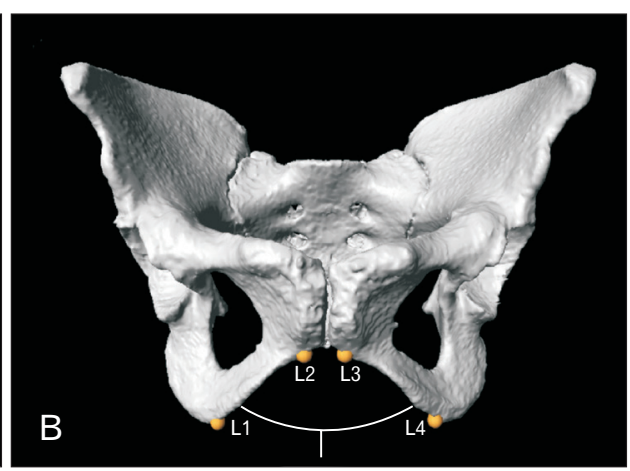

Fig. 2. Three-dimensional computed tomography models of the pelvis showing landmarks in the study. (A) Male pelvis. (B) Female pelvis. L1 and L4, most inferior points on ischiopubic ramus; L2 and L3, most anteroinferior points on symphysis pubis. 
surement was then calculated as the rTEM, also known as \%TEM (Eq. 2).

$$
\% \mathrm{TEM}=\frac{\mathrm{TEM}}{\text { mean }} \times 100
$$

The mean was obtained by calculating the average value for each subject (i.e., summing up the first and second measurements, then divide by two), then the average values for all individuals were added, and divided by the sample size.

The coefficient of reliability (R) was then calculated using Eq. (3). The range for $\mathrm{R}$ is between 0 (not reliable) to 1 (perfect reliability). The $\mathrm{R}$ represents the proportion of betweensubject variance which is free from measurement error [46].

$$
\mathrm{R}=1-\left(\frac{\mathrm{TEM}^{2}}{\mathrm{SD}^{2}}\right)
$$

SD is the standard deviation of all measurements in the sample that was used to assess TEM. The acceptable ranges for rTEM was set at $<1.5 \%$ for intra-observer, and $<2.0 \%$ for inter-observer [46], while $\mathrm{R}>0.95$ was considered an acceptable reliability [42].

\section{Statistical analyses}

Descriptive statistics of the sample population, including the total number of observation $(\mathrm{N})$, minimum, maximum, mean, and SD, were calculated for male and female, separately. The data were normally distributed (determined using Shapiro-Wilk statistic). Independent-sample $t$-test was performed to determine whether the means subpubic angle of male and female were significantly different. Pearson productmoment correlation was performed separately for male and female to determine the direction and strength of correlation between the subpubic angle and age of individuals (age was normally distributed in male and female-determined using Shapiro-Wilk statistic) (Fig. 1). Binary logistic regression was performed to determine the accuracy of sex classification using the subpubic angle. The receiver operating characteristic (ROC) curve analysis and the corresponding area under the curve (AUC) were performed to determine the demarcating

Table 2. Descriptive statistics of subpubic angle $\left(^{\circ}\right)$

\begin{tabular}{cccccc}
\hline \multicolumn{1}{c}{ Sex } & No. & Minimum & Maximum & Mean & SD \\
\hline Male & 50 & 50.8 & 84.6 & 68.6 & 7.6 \\
Female & 50 & 74.0 & 106.5 & 87.4 & 6.5 \\
\hline
\end{tabular}

point of the subpubic angle for sex estimation, and to determine the sensitivity and specificity of this estimation. The data were analyzed using IBM SPSS statistical package for Windows, version 25.0 (IBM Corp., Armonk, NY, USA), and the significance level was set to an alpha level of 0.05.

\section{Results}

The TEMs were calculated at 0.67 and 1.11 for intra- and inter-observer, respectively. The intra-observer rTEM was $0.89 \%$, and inter-observer rTEM was $1.46 \%$ [43]. The coefficient of reliability $(\mathrm{R})$, which is the proportion of variation that is free from measurement error, were 0.997 and 0.992 for intra- and inter-observer, respectively. These results indicated that the present study had achieved the acceptable mark of $<5 \%$ error in measurement [42].

Descriptive statistics for the subpubic angle measurement are presented (Table 2) and depicted graphically (Fig. 3). The subpubic angle of the sample population was between $50.8^{\circ}-106.5^{\circ}\left(78.0^{\circ} \pm 11.8^{\circ}\right)$. In males, the angle was between $50.8^{\circ}-84.6^{\circ}$, and in females between $74.0^{\circ}-106.5^{\circ}$. The independent-sample $t$-test, with an insignificant Levene's test for equality of variances $(\mathrm{t}(98)=13.266, P<0.001, \mathrm{~d}=2.653,95 \%$ confidence interval $[-21.6490$ to -16.0150$])$, revealed that the mean for female subpubic angle $\left(87.4^{\circ} \pm 6.5^{\circ}\right)$ was significantly larger than male subpubic angle $\left(68.6^{\circ} \pm 7.6^{\circ}\right)(P<0.001)$. The $P$-value, 95\% confidence intervals, and Cohen's effect size (d) indicated that the $t$-test was significant and robust, with a huge effect size [47, 48].

The Pearson product-moment correlation coefficients

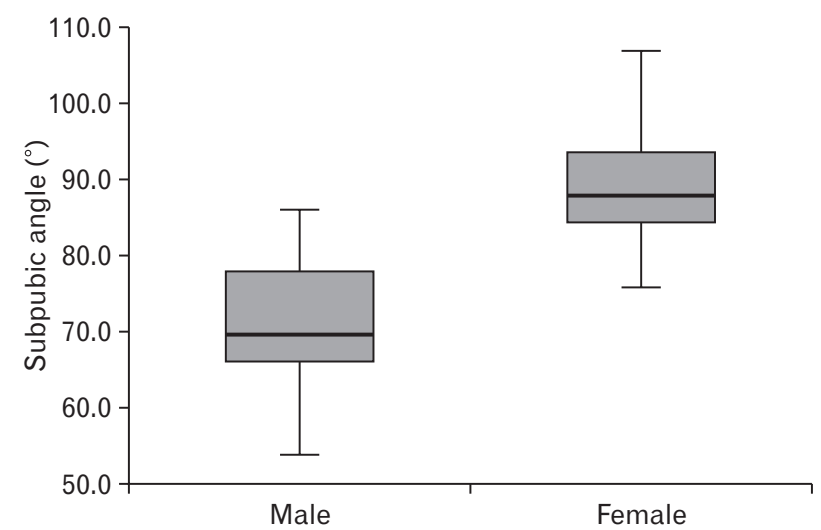

Fig. 3. Box and whisker plot showing the distribution of subpubic angle in males and females. The center line of the box is the median, the bottom line of the box is the 2 nd quartile, and the top line of the box is the 3 rd quartile. The bottom end of the whisker represents the lowest scores, and the top end of the whisker represents the highest scores. 


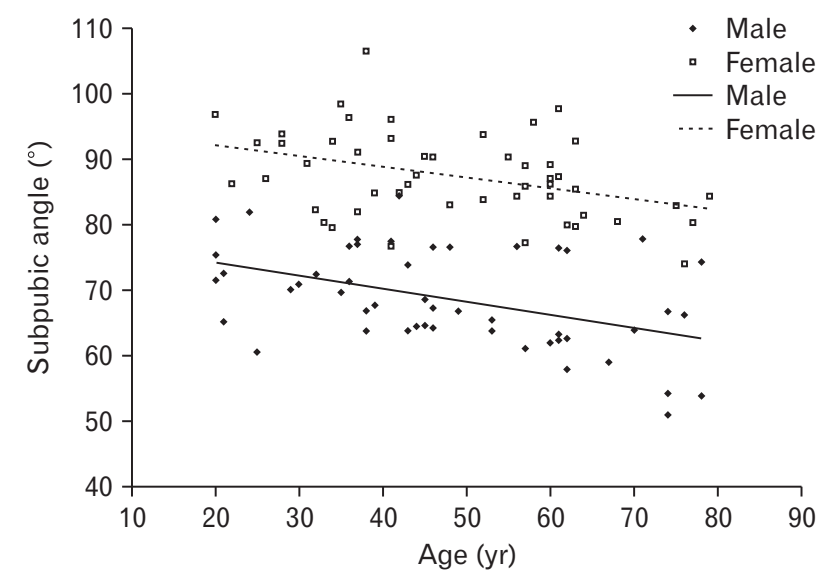

Fig. 4. Scatterplot showing moderate inverse correlation between the subpubic angle and age in males and females (male: $r=-0.449, P<0.001$, female: $r=-0.385, P=0.006$ ).

Table 3. Classification table for sex using the subpubic angle

\begin{tabular}{lccc}
\hline \multirow{2}{*}{ Observed membership } & \multicolumn{3}{c}{ Predicted membership } \\
\cline { 2 - 4 } & Male & Female & Correct (\%) \\
\hline Male & 47 & 3 & 94.0 \\
Female & 3 & 47 & 94.0 \\
Overall classification accuracy (\%) & & & 94.0 \\
\hline
\end{tabular}

revealed that age and subpubic angle were inversely correlated in males, $\mathrm{r}(50)=-0.449(P<0.001)$, and in females, $r(50)=-0.385(P=0.006)$ (Fig. 4$)$. The binary logistic regression revealed that sex estimation using the subpubic angle has an overall accuracy rate of $94 \%(P<0.001)$. Predictions of male and female individuals were both $47 / 50$ correct ( $94 \%$ accurate) (Table 3 ).

From the ROC curve analysis, using a demarcating point of $78.6^{\circ}$, female individuals can be estimated with a sensitivity and specificity of $94 \%$ (Fig. 5). The AUC (0.977) $(P<0.001)$ represented the ability of the subpubic angle to discriminate between male and female. When presented with two random pelvic bones (one male and one female), the subpubic angle would give a correct sex estimation $97.7 \%$ of the time. The 95\% confidence intervals for the subpubic angle from the ROC curve analysis and the AUC, showed that the true AUC for the population would fall between $95.4 \%$ and $100 \%$.

The decision for selecting the value of demarcating point for sex estimation relies on the balance between its sensitivity and specificity in predicting the sex of the individuals [49]. The present study had achieved an optimal balance between the sensitivity and specificity (94\%), by selecting $78.6^{\circ}$, as the demarcating point to discriminate male and female. If a smaller value for the subpubic angle were selected as the

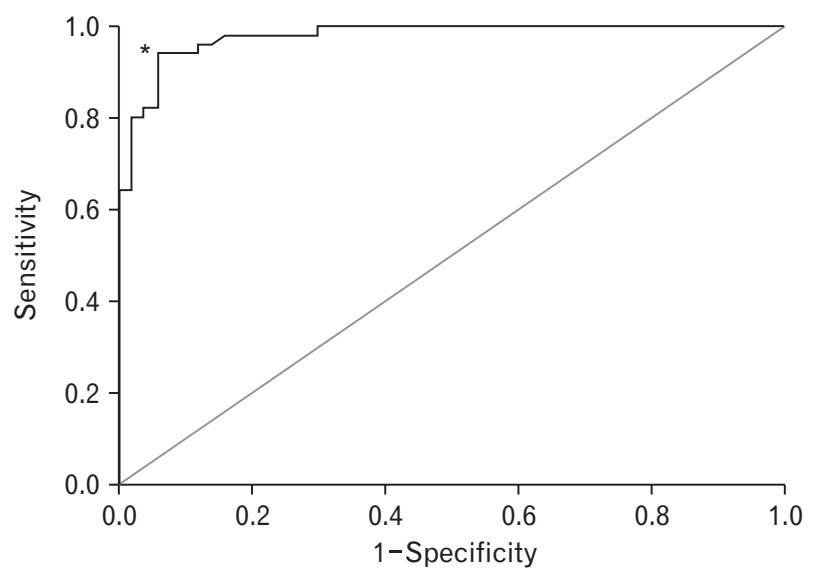

Fig. 5. The receiver operating characteristic curve showing the predictive power of the subpubic angle to discriminate sex. Demarcating point (78.6) that predicts female subject with a sensitivity of 0.94 and 1 -specificity of 0.06 , is marked by the asterisk $\left(^{*}\right)$. Sensitivity and specificity of the subpubic angle at a demarcating point of 78.6 was 94\%. Area under the curve is $0.977(P<0.001)$.

demarcating point, the sensitivity of sex estimation would increase, and more female individuals would be correctly predicted. However, as a trade-off, the specificity would decrease and results in more incorrect estimation of the male individuals [49]. In this study, if a cut-off value of $77^{\circ}$ (sensitivity $96 \%$, specificity $88 \%$ ) was selected as a demarcating point to discriminate between male and female, $96 \%$ of the female individuals will be correctly predicted as female, but $12 \%$ (1specificity) of the male individuals will be incorrectly predicted as female. Thus, a demarcating point of $78.6^{\circ}$ provided the best balance between the sensitivity and specificity for sex estimation, which results in $94 \%$ correctly predicted female individuals (sensitivity), and only $6 \%$ incorrectly predicted male individuals (1-specificity).

\section{Discussion}

According to Krogman and Iscan [50], sex estimation was 95\% accurate when using a complete pelvis, while the ventral arc, subpubic concavity and the medial aspect of ischiopubic ramus had given $96 \%$ accuracy rate [51]. Sex estimation using the subpubic angle, composite arc, and the ventral arc was accurate in $98 \%$ of cases [52]. The role of pelvis in parturition and responsiveness of the subpubic angle to female hormones during growth and puberty [53] may explain the sexual dimorphism of this bone. The subpubic angle is morphologically different between male and female, with a "V-shaped" subpubic angle suggestive of male, while the "U-shaped" sub- 
pubic angle is more likely to be female [ $51,52,54]$. A widely accepted, more straightforward approach to discriminate the pelvis is by using a cut-off value of $90^{\circ}$, subpubic angle $>90^{\circ}$ is indicative of female, and $\angle 90^{\circ}$ is male [55]. This simple discrimination does not apply to all populations, as many researchers showed overlapping values for the subpubic angle of male and female (Table 4) [4, 5, 8, 30, 32-39]. Thus, sex estimation using the cut-off value of $90^{\circ}$ will be inaccurate. The present study also revealed similar results, where the male subpubic angle was between $50.8^{\circ}-84.6^{\circ}\left(68.6^{\circ} \pm 7.6^{\circ}\right)$, and the female subpubic angle between $74.0^{\circ}-106.5^{\circ}\left(87.4^{\circ} \pm 6.5^{\circ}\right)$, with a demarcating point of $78.6^{\circ}$, to discriminate between male and female, in a contemporary Malaysian population.

The results of the present study reaffirmed the established fact that the subpubic angle of the female is generally significantly larger than male (Table 4) [4, 5, 8, 30, 32-39]. The mean

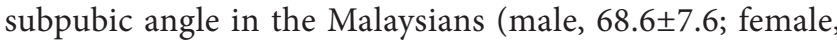
87.4 \pm 6.5 ) were the closest to those of the Australian Caucasians (male, 69.0 \pm 7.3 ; female, 89.4 \pm 7.5 ) [4]. Although the contemporary Japanese and the contemporary Malaysians are

Table 4. Subpubic angle in males and females in different populations

\begin{tabular}{|c|c|c|c|c|c|c|}
\hline Study & Population (country) & Material & Method & Sex & No. & $\mathrm{SPA}\left({ }^{\circ}\right.$, mean $\left.\pm \mathrm{SD}\right)$ \\
\hline \multirow[t]{2}{*}{ Akhlaghi et al. [38] } & \multirow[t]{2}{*}{ Persian (Iran) } & \multirow[t]{2}{*}{ Living subjects } & Anteroposterior & $\mathrm{M}$ & 199 & $101.0 \pm 13.3$ \\
\hline & & & radiographs & $\mathrm{F}$ & 126 & $140.0 \pm 14.3$ \\
\hline \multirow[t]{2}{*}{ Memarian et al. [39] } & \multirow[t]{2}{*}{ Persian (Iran) } & \multirow[t]{2}{*}{ Living subjects } & Anteroposterior & $\mathrm{M}$ & 100 & $101.5 \pm 13.4$ \\
\hline & & & radiographs & $\mathrm{F}$ & 100 & $135.5 \pm 14.8$ \\
\hline \multirow[t]{2}{*}{ Torimitsu et al. [5] } & \multirow[t]{2}{*}{ Asian (Japan) } & \multirow[t]{2}{*}{ Cadavers } & \multirow[t]{2}{*}{ 3DCT images } & $\mathrm{M}$ & 104 & $74.8 \pm 9.58$ \\
\hline & & & & $\mathrm{F}$ & 104 & $112.7 \pm 10.0$ \\
\hline \multirow[t]{2}{*}{ Franklin et al. [4] } & \multirow[t]{2}{*}{ Caucasian (Australia) } & \multirow[t]{2}{*}{ Living subjects } & \multirow[t]{2}{*}{ 3DCT images } & $\mathrm{M}$ & 200 & $69.0 \pm 7.3$ \\
\hline & & & & $\mathrm{F}$ & 200 & $89.4 \pm 7.5$ \\
\hline \multirow[t]{2}{*}{ Karakas et al. [30] } & \multirow{2}{*}{$\begin{array}{l}\text { Anatolian Caucasian } \\
\text { (Turkey) }\end{array}$} & \multirow[t]{2}{*}{ Living subjects } & \multirow[t]{2}{*}{ 3DCT images } & $\mathrm{M}$ & 66 & $65.9 \pm 7.2$ \\
\hline & & & & $\mathrm{F}$ & 43 & $82.6 \pm 7.7$ \\
\hline \multirow[t]{2}{*}{ Small et al. [34] } & \multirow[t]{2}{*}{ White (South Africa) } & \multirow{2}{*}{$\begin{array}{l}\text { Raymond A. Dart } \\
\text { collection }\end{array}$} & \multirow{2}{*}{$\begin{array}{l}\text { Digitization of } \\
\text { reassembled bones }\end{array}$} & $\mathrm{M}$ & 43 & $70.7 \pm 9.4$ \\
\hline & & & & $\mathrm{F}$ & 25 & $93.9 \pm 11.2$ \\
\hline \multirow[t]{2}{*}{ Small et al. [34] } & \multirow[t]{2}{*}{ Black (South Africa) } & \multirow{2}{*}{$\begin{array}{l}\text { Raymond A. Dart } \\
\text { collection }\end{array}$} & Digitization of & $\mathrm{M}$ & 44 & $63.9 \pm 11.1$ \\
\hline & & & reassembled bones & $\mathrm{F}$ & 33 & $84.1 \pm 8.9$ \\
\hline Decker et al. [8] & American (USA) & Living subjects & 3DCT images & $\mathrm{M}$ & 40 & $71.4 \pm 7.8$ \\
\hline & & & & F & 60 & $82.9 \pm 5.7$ \\
\hline Oladipo et al. [32] & African Black (Nigeria) & Living subjects & Projection images & $\mathrm{M}$ & 85 & $100.1 \pm 7.8$ \\
\hline & & & & $\mathrm{F}$ & 173 & $119.4 \pm 3.9$ \\
\hline Oladipo et al. [32] & African Black (Nigeria) & Living subjects & Projection images & M & 129 & $105.6 \pm 3.0$ \\
\hline & & & & $\mathrm{F}$ & 213 & $125 \pm 3.2$ \\
\hline Msamati et al. [33] & African Black (Nigeria) & Living subjects & Anteroposterior & $\mathrm{M}$ & 73 & $99.2 \pm 15.7$ \\
\hline & & & radiographs & $\mathrm{F}$ & 46 & $129.1 \pm 14.2$ \\
\hline Igbigbi and Nanono- & African Black (Nigeria) & Living subjects & Anteroposterior & $\mathrm{M}$ & 110 & $93.9 \pm 21.2$ \\
\hline Igbigbi [35] & & & radiographs & $\mathrm{F}$ & 95 & $116.1 \pm 17.8$ \\
\hline Tague [37] & American White (USA) & Hamman-Todd & Projection images & $\mathrm{M}$ & 50 & $63.7 \pm 7.8$ \\
\hline & & collection & & $\mathrm{F}$ & 50 & $88.4 \pm 12.3$ \\
\hline Tague [37] & American Black (USA) & Hamman-Todd & Projection images & $\mathrm{M}$ & 50 & $65.8 \pm 8.7$ \\
\hline & & collection & & $\mathrm{F}$ & 49 & $85.2 \pm 10.4$ \\
\hline Tague [37] & Amerindian (USA) & Indian Knoll & Projection images & $\mathrm{M}$ & 74 & $73.8 \pm 8.4$ \\
\hline & & & & $\mathrm{F}$ & 58 & $98.2 \pm 8.4$ \\
\hline Tague [37] & Amerindian (USA) & Pecos Pueblo & Projection images & $\mathrm{M}$ & 104 & $61.6 \pm 8.2$ \\
\hline & & & & $\mathrm{F}$ & 114 & $86.0 \pm 10.0$ \\
\hline Tague [37] & Amerindian (USA) & Libben & Projection images & $\mathrm{M}$ & 46 & $68.8 \pm 7.8$ \\
\hline & & & & $\mathrm{F}$ & 21 & $95.2 \pm 10.8$ \\
\hline Tague [37] & Amerindian (USA) & Haida & Projection images & $\mathrm{M}$ & 29 & $65.4 \pm 8.2$ \\
\hline & & & & $\mathrm{F}$ & 19 & $93.0 \pm 12.3$ \\
\hline Young and Ince [36] & White European & Living subjects & Anteroposterior & $\mathrm{M}$ & 50 & $75.8 \pm 5.8$ \\
\hline & (England) & & radiographs & $\mathrm{F}$ & 500 & $93.5 \pm 7.4$ \\
\hline Present study & Asian (Malaysia) & Living subjects & 3DCT images & $\mathrm{M}$ & 50 & $68.6 \pm 7.6$ \\
\hline & & & & $\mathrm{F}$ & 50 & $87.4 \pm 6.5$ \\
\hline
\end{tabular}

SPA, subpubic angle; M, male; F, female; 3DCT, three-dimensional computed tomography. 


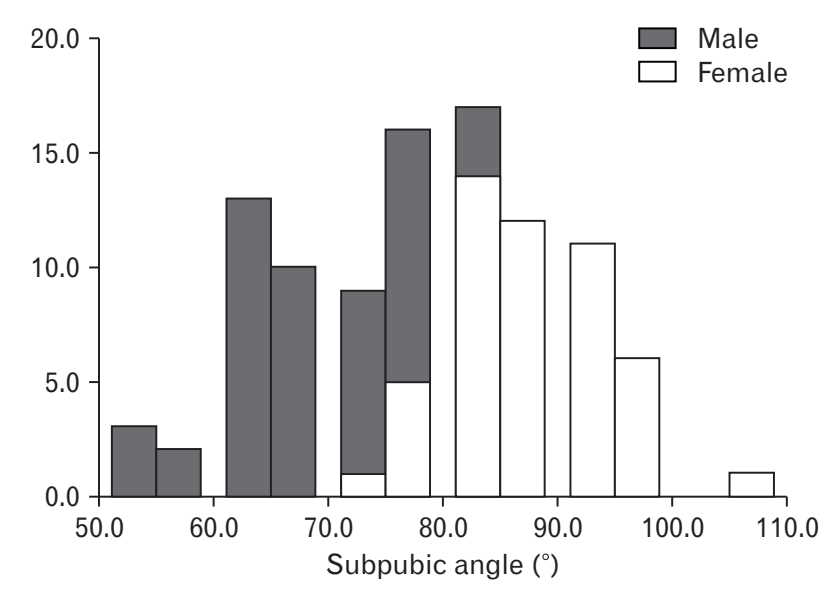

Fig. 6. Histogram showing the distribution of subpubic angle in male and female. Demarcating point for sex discrimination is 78.6.

from the Asian continent, their mean subpubic angles were somewhat different. The Japanese had much larger subpubic angles for both male and female (male, $74.8 \pm 9.58$; female, $112.7 \pm 10.0$ ) [5] compared to the Malaysians. The values of subpubic angles of the Malaysians and these populations (Australian Caucasians and Japanese) were comparable as these studies had also used 3DCT models. Other studies had employed different methods, including anteroposterior radiographs, projection images, and digitization of reassembled bones (Table 4) [4, 5, 8, 30, 32-39], which may explain the differences in the subpubic angle compared to the present study.

The accuracy of sex estimation using the subpubic angle in this study was $94 \%$. Using a demarcating point of $78.6^{\circ}$, the sensitivity and specificity of subpubic angle to detect the female individuals were both $94 \%$ (Table 3, Fig. 6). Other studies had also achieved high accuracy rate in sex estimation using the subpubic angle alone; Karakas et al. [30] had reached an accuracy rate of $90.8 \%$, while Small et al. [34] had shown an $86 \%$ accuracy rate. These rates were highly regarded as only one parameter was used, which were comparable to others that used discriminant function formulae (Steyn and Işcan [56] on Greek sample [95\%], Schulter-Ellis et al. [57] on American sample [95\%-98\%], Mahakkanukrauh et al. [2] on Thai sample [94.4\%] and Patriquin et al. [58] on South African sample [91\%]).

The present study showed that the subpubic angle was inversely related to age. Coefficient of determination $\left(\mathrm{r}^{2}\right)$, showed $20.2 \%$ and $14.8 \%$ of variations in the subpubic angle, was contributed by age in male and female, respectively (Fig. 4). The involvement of pelvis in the pelvis-spine balance system for sitting position [59], may explain the inverse cor- relation between subpubic angle and age found in the present study. As an adaptation to its role in this system, the distance between the ischial tuberosities of the pelvis decreases with age [60]. Narrowing of the bituberous diameter in this agerelated adaptive process results in a smaller subpubic angle in older individuals [61].

In the binary logistic regression, the incorrectly predicted individuals were aged 20,24, and 42 years for the males (predicted to be female), and 41, 57, and 76 years for the females (predicted to be male). The correlation of age and the subpubic angle may explain these observations, younger males had a larger subpubic angle, thus predicted as female, and older females had a smaller subpubic angle, thus predicted as male. However, Karakas et al. [30] did not find any relationship between the subpubic angle and age, while Nwoha [62] had documented an opposite result, whereby there was a larger subpubic angle in the older individuals compared to the younger ones. Karakas et al. [30] had used the Pearson correlation coefficient test; similar to the present study, while Nwoha [62] had used Student's $t$-test. Incongruence in observations made by this study in comparison with other studies may be explained by genetics, geography, ancestry, and different methods employed (anteroposterior radiographs), as in the study by Nwoha [62]. Other factors that may contribute include the effects of secular change, climate, nutrition, lifestyle activities, childbirth and parturition, hormones, and types of labor or activities [13, 15, 16, 53, 55].

\section{Conclusion}

The female subpubic angle was significantly larger than males in a contemporary Malaysian population, and sex estimation using the subpubic angle is highly accurate, with a high level of expected sensitivity and specificity. It can be concluded that the subpubic angle may be used for investigative anthropometry and forensic studies in Malaysia, complementary with other methods for sex estimation. In actual forensic cases, the demarcating point of the subpubic angle from this study may be used when the recovered pelvic bone is complete. Other methods should be employed when only one side of the ossa coxae is available.

\section{ORCID}

Siti Hanum Mohd Ali: http://orcid.org/0000-0003-1043-6740

Normaliza Omar: http://orcid.org/0000-0003-2733-9437

Mohamed Swarhib Shafie: 
http://orcid.org/0000-0001-6656-3904

Nik Azuan Nik Ismail:

http://orcid.org/0000-0002-1531-8623

Helmi Hadi: http://orcid.org/0000-0002-3225-8327

Faridah Mohd Nor: http://orcid.org/0000-0003-0678-825X

\section{Author Contributions}

Conceptualization: SHMA, FMN. Data acquisition: SHMA, NO, MSS, NANI, HH, FMN. Data analysis or interpretation: SHMA, NO, FMN. Drafting of the manuscript: SHMA, NO, FMN. Critical revision of the manuscript: SHMA, FMN. Approval of the final version of the manuscript: all authors.

\section{Conflicts of Interest}

No potential conflict of interest relevant to this article was reported.

\section{Acknowledgements}

The authors thank the staff in the Radiology department for giving access to the CT scan images for the study. We also offer our thanks to Universiti Kebangsaan Malaysia for financing the research project.

\section{References}

1. King CA, Işcan MY, Loth SR. Metric and comparative analysis of sexual dimorphism in the Thai femur. J Forensic Sci 1998;43: 954-8.

2. Mahakkanukrauh P, Ruengdit S, Tun SM, Case DT, Sinthubua A. Osteometric sex estimation from the os coxa in a Thai population. Forensic Sci Int 2017;271:127.

3. Dabbs GR, Moore-Jansen PH. A method for estimating sex using metric analysis of the scapula. J Forensic Sci 2010;55:149-52.

4. Franklin D, Cardini A, Flavel A, Marks MK. Morphometric analysis of pelvic sexual dimorphism in a contemporary Western Australian population. Int J Legal Med 2014;128:861-72.

5. Torimitsu S, Makino Y, Saitoh H, Sakuma A, Ishii N, Yajima D, Inokuchi G, Motomura A, Chiba F, Yamaguchi R, Hashimoto M, Hoshioka Y, Iwase H. Morphometric analysis of sex differences in contemporary Japanese pelves using multidetector computed tomography. Forensic Sci Int 2015;257:530.

6. Praneatpolgrang S, Prasitwattanaseree S, Mahakkanukrauh P. Age estimation equations using vertebral osteophyte formation in a Thai population: comparison and modified osteophyte scoring method. Anat Cell Biol 2019;52:149-60.

7. Sinthubua A, Ruengdit S, Das S, Mahakkanukrauh P. A new method for sex estimation from maxillary suture length in a Thai population. Anat Cell Biol 2017;50:261-4.

8. Decker SJ, Davy-Jow SL, Ford JM, Hilbelink DR. Virtual determination of sex: metric and nonmetric traits of the adult pelvis from 3D computed tomography models. J Forensic Sci 2011;56: 1107-14.

9. Dixit SG, Kakar S, Agarwal S, Choudhry R. Sexing of human hip bones of Indian origin by discriminant function analysis. J Forensic Leg Med 2007;14:429-35.

10. Betti L. Human variation in pelvic shape and the effects of climate and past population history. Anat Rec (Hoboken) 2017;300: 687-97.

11. Allen J. The influence of physical conditions in the genesis of species. Radic Rev 1877;1:108-40.

12. Bergmann K. On the relations of the heat economy of animals to their size. Gottinger Stud 1847;3:595-708.

13. Kurki HK. Bony pelvic canal size and shape in relation to body proportionality in humans. Am J Phys Anthropol 2013;151:88101.

14. Patriquin ML, Steyn M, Loth SR. Metric assessment of race from the pelvis in South Africans. Forensic Sci Int 2002;127:104-13.

15. Klales AR. Secular change in morphological pelvic traits used for sex estimation. J Forensic Sci 2016;61:295-301.

16. Betti L, von Cramon-Taubadel N, Manica A, Lycett SJ. The interaction of neutral evolutionary processes with climatically-driven adaptive changes in the $3 \mathrm{D}$ shape of the human os coxae. J Hum Evol 2014;73:64-74.

17. Ruff CB. Morphological adaptation to climate in modern and fossil hominids. Am J Phys Anthropol 1994;37:65-107.

18. Işcan MY, İşcan MY. Forensic anthropology of sex and body size. Forensic Sci Int 2005; 147:107-12.

19. Noorain S, Alias A, Abdullah N, Judi HM, Shafie MS, Das S, Ibrahim A, Mohd Nor F. Stature estimation by using upper limb measurements in the Malaysian population. Int Med J 2018;25:391-4.

20. Ibrahim A, Alias A, Nor FM, Swarhib M, Abu Bakar SN, Das S, Abdullah N, Noor MHM. Erratum: Study of sexual dimorphism of Malaysian crania: an important step in identification of the skeletal remains. Anat Cell Biol 2019;52:219.

21. Ibrahim A, Attalla SM, Alias A, Swarhib M, Abu Bakar SN, Das S, Mohd Nor F. Osteometric analysis of supraorbital foramen and notch in Malaysian crania. Asian J Pharm Clin Res 2018;11:50912.

22. Alias A, Ibrahim A, Abu Bakar SN, Swarhib Shafie M, Das S, Abdullah N, Noor HM, Liao IY, Mohd Nor F. Anthropometric analysis of mandible: an important step for sex determination. Clin Ter 2018;169:e217-23.

23. Mak H, Moorthy TN. Stature estimation from the anthropometric measurements of footprint in Iban ethnics of East Malaysia by regression analysis. J Forensic Sci Criminol 2014;2:201.

24. Moorthy TN, Yin TY. Regression analysis to determine stature from fingerprints in Malaysian. J Bio Innov 2016;5:411-8.

25. Omar N, Mohd Ali SH, Shafie MS, Nik Ismail NA, Hadi H, Mohd Nor F. A preliminary study of sexual dimorphism of 
scapula by computed tomography in the Malaysian population. Asian J Pharm Clin Res 2019;12:391-5.

26. Ismail NA, Abd Khupur NH, Osman K, Mansar AH, Shafie MS, Mohd Nor F. Stature estimation in Malaysian population from radiographic measurements of upper limbs. Egypt J Forensic Sci 2018;8:22.

27. Bolliger SA, Thali MJ, Ross S, Buck U, Naether S, Vock P. Virtual autopsy using imaging: bridging radiologic and forensic sciences. A review of the Virtopsy and similar projects. Eur Radiol 2008; 18:273-82.

28. Franklin D, Swift L, Flavel A. "Virtual anthropology" and radiographic imaging in the forensic medical sciences. Egypt J Forensic Sci 2016;6:31-43.

29. Franklin D, Cardini A, Flavel A, Kuliukas A, Marks MK, Hart R, Oxnard C, O'Higgins P. Concordance of traditional osteometric and volume-rendered MSCT interlandmark cranial measurements. Int J Legal Med 2013;127:505-20.

30. Karakas HM, Harma A, Alicioglu B. The subpubic angle in sex determination: anthropometric measurements and analyses on Anatolian Caucasians using multidetector computed tomography datasets. J Forensic Leg Med 2013;20:1004-9.

31. Washburn SL. Sex differences in the pubic bone of Bantu and Bushman. Am J Phys Anthropol 1949;7:425-32.

32. Oladipo GS, Ugboma HA, Suleiman YA. Comparative study of the sub-pubic angles of adult Ijaws and Igbos. Asian J Med Sci 2009;1:26-9.

33. Msamati BC, Igbigbi PS, Manda JK. The sub-pubic angle in adult indigenous Malawian subjects. East Afr Med J 2005;82:643-8.

34. Small C, Brits DM, Hemingway J. Quantification of the subpubic angle in South Africans. Forensic Sci Int 2012;222:395.

35. Igbigbi PS, Nanono-Igbigbi AM. Determination of sex and race from the subpubic angle in Ugandan subjects. Am J Forensic Med Pathol 2003;24:168-72.

36. Young M, Ince JG. A radiographic comparison of the male and female pelvis. J Anat 1940;74(Pt 3):374-85.

37. Tague RG. Variation in pelvic size between males and females. Am J Phys Anthropol 1989;80:59-71.

38. Akhlaghi M, Bakhttavar K, Mokhtari T, Mehdizadeh F, Parsa VA, Farahani MV, Farahani MV, Sadeghian MH. Research paper: using subpubic angle in sex determination and stature estimation. An anthropometric study on Iranian adult population. Int J Med Toxicol Forensic Med 2017;7:195-202.

39. Memarian A, Aghakhani K, Mehrpisheh S, Fares F. Gender determination from diagnostic factors on anteroposterior pelvic radiographs. J Chin Med Assoc 2017;80:161-8.

40. Fedorov A, Beichel R, Kalpathy-Cramer J, Finet J, Fillion-Robin JC, Pujol S, Bauer C, Jennings D, Fennessy F, Sonka M, Buatti J, Aylward S, Miller JV, Pieper S, Kikinis R. 3D Slicer as an image computing platform for the Quantitative Imaging Network. Magn Reson Imaging 2012;30:1323-41.

41. Zelditch M, Swiderski D, Sheets HD, Fink W. Geometric morphometrics for biologist. London: Academic Press; 2004.

42. Ulijaszek SJ, Kerr DA. Anthropometric measurement error and the assessment of nutritional status. Br J Nutr 1999;82:165-77.
43. Perini TA, de Oliveira GL, dos Santos Ornelia J, de Oliveira FP. Technical error of measurement in anthropometry. Rev Bras Med Esporte 2005;11:86-90.

44. Brown KM. Selective pressures in the human bony pelvis: decoupling sexual dimorphism in the anterior and posterior spaces. Am J Phys Anthropol 2015;157:428-40.

45. Ridgeway BM, Arias BE, Barber MD. Variation of the obturator foramen and pubic arch of the female bony pelvis. Am J Obstet Gynecol 2008;198:546.

46. Weinberg SM, Scott NM, Neiswanger K, Marazita ML. Intraobserver error associated with measurements of the hand. Am J Hum Biol 2005; 17:368-71.

47. Cohen J. Statistical power analysis for the behavioral sciences. 2nd ed. Hilldsdale, NJ: Lawrence Erlbaum Associates; 1988.

48. Sawilowsky SS. New effect size rules of thumb. J Mod Appl Stat Methods 2009;8:26.

49. Portney LG, Watkins MP. Foundations of clinical research: applications to practice. 3rd ed. Philadelphia, PA: F.A Davis Company; 2015.

50. Krogman WM, Iscan MY. Human skeleton in forensic medicine. Springfield, IL: Charles C. Thomas; 1986.

51. Phenice TW. A newly developed visual method of sexing the os pubis. Am J Phys Anthropol 1969;30:297-301.

52. Durić M, Rakocević Z, Donić D. The reliability of sex determination of skeletons from forensic context in the Balkans. Forensic Sci Int 2005;147:159-64.

53. Washburn SL. Sex differences in the pubic bone. Am J Phys Anthropol 1948;6:199-207.

54. Listi GA, Bassett HE. Test of an alternative method for determining sex from the os coxae: applications for modern Americans. J Forensic Sci 2006;51:248-52.

55. Rösing FW, Graw M, Marré B, Ritz-Timme S, Rothschild MA, Rötzscher K, Schmeling A, Schröder I, Geserick G. Recommendations for the forensic diagnosis of sex and age from skeletons. Homo 2007;58:75-89.

56. Steyn M, Işcan MY. Metric sex determination from the pelvis in modern Greeks. Forensic Sci Int 2008;179:86.

57. Schulter-Ellis FP, Hayek LC, Schmidt DJ. Determination of sex with a discriminant analysis of new pelvic bone measurements: Part II. J Forensic Sci 1985;30:178-85.

58. Patriquin ML, Steyn M, Loth SR. Metric analysis of sex differences in South African black and white pelves. Forensic Sci Int 2005;147:119-27.

59. Lovejoy CO. Evolution of human walking. Sci Am 1988;259:11825.

60. Moes NC. Variation in sitting pressure distribution and location of the points of maximum pressure with rotation of the pelvis, gender and body characteristics. Ergonomics 2007;50:536-61.

61. Kolesova O, Kolesovs A, Vetra J. Age-related trends of lesser pelvic architecture in females and males: a computed tomography pelvimetry study. Anat Cell Biol 2017;50:265-74.

62. Nwoha PU. The anterior dimensions of the pelvis in male and female Nigerians. Afr J Med Med Sci 1995;24:329-35. 